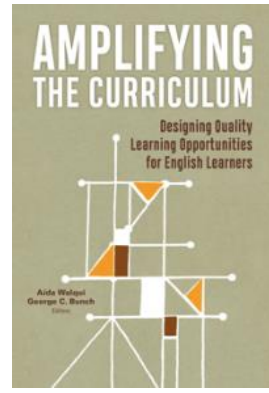

Walqui, A. \& Bunch, G. C. (Eds.). (2019). Amplifying the curriculum: Designing quality learning opportunities for English learners. New York, NY: Teachers College Press. 241 pp., ISBN: 9780807761199. \$29.95 (Print).

\title{
Maximizing Educational Opportunities for English Learners Through Amplified Curriculum
}

\author{
Carla Huck1 \\ Florida Gulf Coast University
}

This book, published by Teacher College Press, is a continuation and expansion of the curriculum work that editors Aida Walqui and George Bunch started as founding members of Stanford University's Understanding Language Initiative in 2010. Walqui and Bunch enlisted the aid of colleagues at the University of Santa Cruz, where Bunch is a professor of education, and at WestEd where Walqui directs the Quality Teaching for English Learners (QTEL) program, along with teachers and teacher educators to contribute models for curriculum and instruction across content areas. Walqui and Bunch authored five of the ten chapters, providing the roadmap for enacting shifts in curriculum design for quality interactions and engagement in language practices. The goal of this book is to help transform teacher practice from one of simplification to amplification, designing learning opportunities through a structured framework that best maximizes the potential of English Learners. 1

What is quality instruction for English Learners? While many experts in the field agree on the essential components, the editors start with the premise that teachers must, "Amplify, don't simplify!" Traditionally, teachers have separated language from content, resulting in simplified content presented to English Learners thereby limiting quality learning opportunities. No matter their background, it is important to view English Learners with an asset-based lens and to provide optimal opportunities for them to thrive academically, participate civically, and engage in productive careers. When given the opportunity and appropriate support, English Learners can access complex and challenging grade-level texts and ideas in ways that many teachers would not have thought possible.

The authors propose a framework for designing meaningful and deep learning opportunities, with example "amplified" learning tasks to promote student consideration of powerful ideas that are interconnected and critically discussed through structured interactions. This type of strategic planning provides optimum learning of subject area content, language, and literacy beyond use of a collection of discrete instructional strategies. The general movement toward school practices that support deeper learning has been shown to benefit low-income and minority students, and the authors cite research from Noguera et al. (2017) revealing cycles of inequitable schooling opportunities that need to be disrupted (pp. 7-8). Walqui and Bunch believe that teachers are central to this shift toward more intellectually substantive, socially relevant practices for all students.

1 E-mail: chuck@fgcu.edu 
While the content is applicable to all grade levels, the authors have targeted this text for secondary level curricula in particular because content, language, and literacy demands increase at these grade levels. The authors clarify that this is not a proposal for curriculum to be handed to teachers to follow, but rather teachers should be active developers of curriculum using the framework provided. The framework is anchored in five key tenets (p. 23):

1. Development emerges in social interaction. It is a consequence of, not a prerequisite for, learning.

2. Quality learning is deliberately and contingently scaffolded.

3. Quality school learning focuses on substantive and generative disciplinary practices.

4. During learning, English Learners simultaneously develop conceptual, analytic, and language practices.

5. When it comes to the development of language practices, quality learning opportunities for English Learners focus on form in contextual, contingent, and supportive ways.

Walqui and Bunch believe that the curriculum requires a spiraling rather than a linear organization. Important key concepts are introduced, revisited, expanded upon, and revisited over time through different contexts. It is important to note that the goal of each lesson must be made clear, and considered meaningful, to the learners. Building on Vygotsky's (1978) Zone of Proximal Development (ZPD), the authors apply this concept to the pedagogical setting as not a fixed attribute of the individual learner, but rather "a dynamic, interactive space created to afford a group of learners the opportunity to construct needed understandings" (p. 25). These "affordances" provide learners multiple opportunities for constructing meaning, making connections, problemsolving, and growth. There is coherence across tasks, lessons, and units, with each task helping students move toward the goals of the lesson which is part of a unit of study exploring an essential question. Students are actively engaged in both self-assessment and peer assessment toward reaching well-defined goals. The authors deftly weave Vygotsky's concept of the ZPD through each unit of study, demonstrating that the dynamic, interactive space created through learner interactions provides the opportunity to negotiate meaning and construct understanding even for those students at beginning levels of language proficiency.

In Chapter 3, the authors suggest that lessons be designed along three key "moments" named after what students accomplish with concepts or texts: Preparing Learners (focusing and activating prior knowledge or building the field); Interacting with Text or Concept; and Extending Understanding. These moments are explained in detail in the context of a unit on "Power, Protest, and Change" prepared for a high school class of long-term English Learners. As they progress through the carefully sequenced and scaffolding unit, students develop precise understanding of key concepts through critical reading, evaluation, and discussion of multimodal texts. They analyze author's perspective with attention to tone and positionality, develop critical stances of their own, and write an essay demonstrating deep understanding of the unit's theme. Most significant in this chapter is the inclusion of artifacts from the classroom: a silent graffiti sample with photo of students at work; graphic organizers such as a photograph note-taker, double-entry journal, compare/contrast matrix, claims and counterclaims chart, and language detective table; and a clarifying bookmark to assist students in working through the text applying metacognitive strategies.

The authors also address the challenges that many educators will raise when asked to design powerful lessons for their English Learners, and their recommended responses from an administrator or instructional coach. If teachers lack subject matter knowledge, explain that this knowledge will be deepened through the search for appropriate materials and texts to use. If 
teachers lack pedagogical disciplinary language knowledge, assure them that they need not be linguists, rather be aware of the language demands of their discipline. If time is the issue, which ideally would be provided in school during professional learning communities, suggest that collaborating with peers and investing time in quality lessons will yield great results that can be used year after year. Finally, if faced with mandated curricula and pacing guides, then the authors caution that this type of "intractable challenge" will have devastating consequences for the quality of education provided to English Learners.

In Chapters 4-7 the various teams of authors provide examples of specific unit plans, lessons, and learning activities across content areas of English Language Arts (ELA), science, mathematics, and social studies that demonstrate effective instructional design with amplification for English Learners. These units serve as exemplars for the disciplinary approach, with practical and well-illustrated implementation of amplification practices through each phase of the lessons. The high level of support provided by the instructional design of each unit is clearly described and visually represented through templates and figures, with a description and purpose for each strategy used in the three-moment framework.

In Chapter 4, Shakespeare's Macbeth: Making Powerful Texts Accessible and Engaging to English Learners, author Mary Shmida addresses the concern that many teachers have with using longer texts. She demonstrates how to select only pivotal and key moments in texts such as MacBeth to allow time for deeper engagement activities, while providing students with summaries of other scenes that they will not read. Learners prepare for lessons through think-pair-share about concepts of power; listen with focus to select passages and complete a double entry journal on character motivation using evidence from text; discuss quotes with peers and reach consensus on meaning; and assume a critical stance as they analyze character perspectives. When learning is strategically planned in this manner, students are able to read the original version of the play rather than a simplified version.

In Chapter 5, readers learn how to design experiences that engage English Learners in considering scientific concepts with real-life implications. The authors have designed a highly interactive unit, Investigating Disease Transmission, with the goal of developing student understanding of communicable disease spread and ways to prevent transmission. Students further their conceptual and linguistic understanding through a series of sequenced tasks; practice analytical skills through experimental design and data analysis; role play as members of the World Health Organization, and communicate knowledge through supports such as anticipation guides and graphic organizers. At each step in the three-moment architecture, teachers may formatively assess student progress and determine ways to further develop science learning and language development.

Using the Chapter 6 lesson "A Less Slippery Slope" as a reference, teachers of mathematics can undertake key actions to design rigorous lessons that develop a clear, conceptual focus, tap into students' experiences and knowledge, and foster quality peer interactions for co-construction of understanding. The authors of this chapter demonstrate multiple ways to engage students in mathematical practices using the concept of slope, starting with discussion of climbing, steepness, and slope then moving into reading and interpreting texts about vertical and horizontal changes in tables and graphs. After students have engaged in these key standards-based practices of "looking for and making use of structure" and "attending to precision" they are ready to "make sense of problems and persevere in solving them" (p. 131). By the end of the lesson, students will have generated a poster applying the concept of slope to solving a real life problem and written a letter of advice for a construction project. It is important to note that these well-structured activities to 
foster deep mathematics understanding are critical for English Learners, yet beneficial to all students.

In Chapter 7 the three-moment architecture is applied to a social studies lesson, "Mapping a Changing World View." Students develop an awareness of maps as human constructions that reflect contemporary understandings of the world, they apply historical thinking skills to analyze primary and secondary documents, and they participate in sustained conversations using the reasoning and language of historians. The three historic maps used as multimodal primary source texts for the lesson assist students in locating visual discrepancies they might not have discovered through written texts alone. Following the format of the previous chapters, the authors have presented a table of sequenced learning tasks along with sample artifacts for classroom adaptation.

The format of Chapter 8 is similar to that of the previous four chapters in that the authors present a lesson designed with the three-moment architecture, choosing a culminating task and planning backward; however rather than focusing on a specific discipline they address a specific group of learners: beginning-level English Learners who are often newcomers to the United States. This unit, designed collaboratively by three teachers at the International Newcomers Academy in Fort Worth, Texas, addresses the theme, "What Makes Me Who I Am?" by moving from concrete to more abstract ideas. The teachers carefully scaffolded tasks aligned to texts, with rigorous conceptual and linguistic goals demonstrating high expectations for students. This unit in particular illuminates how teachers of secondary newcomers need not hold students back from challenging, grade level content until they have "mastered" enough English for these tasks, which is often the case in these types of classes. An important piece of advice for teachers is to use excerpts from challenging, grade-level text, and analyze them deeply, rather than push students through the entire selection. This concept illustrates "amplification" through elaboration, guiding, and chunking of the original text instead of finding a simplified, "ESL-friendly" version.

In Chapter 9, the authors discuss challenges and opportunities reported by teachers in three cities who implemented a pilot unit designed to exemplify amplified curriculum. This seventh grade unit, Persuasion Across Time and Space, was developed by Walqui, Bunch, and several associates shortly after Common Core Standards had been adopted by most states. The authors aimed to illuminate a number of pedagogical shifts in designing learning opportunities for English Learners as a result of the language demands in these new standards. The teachers in the study reported their surprise at the ability of their students to engage with challenging and complex texts (e.g., Gettysburg Address; Civil Rights Movement speeches) through spiraling, scaffolding supports, and collaborative structures. Their comments reflected prior low expectations for English Learners and lack of prior pedagogical expertise to amplify curriculum. The students in the study reported feeling positively challenged from working collaboratively with peers to decipher the language of their mentor texts, to communicate ideas with academic language, and to contribute their own experiences to the concepts and contexts of the unit.

In the final chapter, Walqui and Bunch address the complex nature of developing teacher pedagogical expertise in designing and implementing amplified curriculum for English Learners.

They support the backwards planning approach to curriculum, which is to "start with the end in mind" (p. 209). Throughout the process of preparing - activating prior knowledge, building background, setting objectives, designing tasks to guide students toward interaction with and sensemaking of ideas in the text, and developing opportunities for students to extend their understanding - the authors contend that students must be engaged in substantive interactions. "With the destination in mind, well-designed lessons take students by the hand to lead them along a road where they increasingly take the responsibility for their journey" (p. 67).

Walqui (2007) has included her Model of Teacher Understanding as adapted from Shulman with an explanation of the six domains of understanding that teachers develop through professional 
practice. This scholarly part of the chapter would be most useful for teacher educators designing curriculum and experiences related to domains of understanding, and the chapter concludes with suggestions for professional development and teacher preparation.

Amplifying the Curriculum is not only a detailed guide to curriculum design for teachers of English Learners, but a primer on lesson planning that combines research-based literacy practices, principles of second language acquisition, and integration of conceptual, analytic, and language practices. The authors have met their objective of providing a clear framework as well as practical guidance and examples for teachers and those who support them as they develop curriculum and learning environments that will maximize English Learners' potential. I would highly recommend this book to middle and high school teachers, administrators, and instructional coaches because it addresses ways to tackle complex academic language through scaffolding, which is critical to every instructional framework addressing the needs of English learners (Walqui \& van Lier, 2010). I would also support the reading of this text in teacher preparation programs, as the increasing inclusion of English Learners in mainstream classes necessitates strong preparation of all teachers to provide effective instruction to this unique population of students. Schools, professional development initiatives, and teacher educators can employ this text to help transform teachers from deliverers of simplified curriculum to designers of amplified curriculum.

\section{Notes}

1. As the authors discuss in Chapter 1, the term English Learner has multiple meanings and it is used to refer to the five million students in U.S. schools who come from different geographic, linguistic, educational, and socioeconomic backgrounds. While the term has been criticized in recent years due to the deficit associations and negative consequences this label can hold for students, they assert that it represents a statutory category in federal law that is meant to foster a positive impact for students. This is the term used in the Elementary and Secondary Education Act (ESEA) by the U.S. Department of Education (2016, p. 43) and the authors emphasize the diverse nature of each learner depending on his or her context.

\section{References}

Noguera, P., Darling-Hammond, L., \& Friedlander, D. (2017). Equal opportunity for deeper learning. In R. Heller, R. E. Wolfe, \& A. Stenberg (Eds.), Rethinking readiness: Deeper learning for college, work, and life (pp. 81-104). Boston, MA: Harvard Education Press.

U.S. Department of Education. (2016). Non-regulatory guidance: English Learners and Title III of the Elementary and Secondary Education Act (ESEA), as amended by the Every Student Succeeds Act (ESSA). U.S. Department of Education. https://www2.ed.gov/policy/elsec/leg/essa/essatitleiiiguidenglishlearners92016. pdf

Vygotsky, L. (1978). Mind in society. Boston, MA: Harvard University Press.

Walqui, A. (2007). The development of teacher expertise to work with adolescent English learners: A model and a few priorities. In L. S. Verplaetse \& N. Migliacci (Eds.), Inclusive pedagogy for English language learners: A handbook of research-informed practices (pp. 103-125). New York, NY: Lawrence Erlbaum Associates.

Walqui, A., \& van Lier, L. (2010). Scaffolding the academic success of adolescent English language learners: A pedagogy of promise. San Francisco, CA: WestEd. 
Huck, C.

\section{Notes on Contributors}

Carla B. Huck is a doctoral student at Florida Gulf Coast University in Fort Myers, FL., where she also instructs pre-service teachers in ESOL endorsement courses. She has an M.A. in TESOL and an Ed.M in Urban Education Administration. She currently serves as the ELL Instructional Leader for the School District of Lee County, and is the founder/President of SouthWest Florida TESOL. 